This is an open access article under the CC BY-NC-ND license (https://creativecommons.org/licenses/by-nc-nd/3.0/) Issue III, November 2020

ISSN 2707-9481

ISBN 978-601-323-207-2

https://doi.org/10.31643/2020.011

\author{
Aigul Akhmetova \\ Abai Kazakh National Pedagogical University, \\ Kazakhstan. E-mail: aig.31@mail.ru \\ ORCID ID 0000-0002-9292-5515
}

Gulzhaina Kassymova

Abai University, Satbayev University, Kazakhstan.

E-mail: g.kassymova@ satbayev.university

ORCID ID 0000-0001-7004-3864

\author{
Auyelkhan Toktaubay \\ Abai Kazakh National Pedagogical University, \\ Kazakhstan. E-mail: fertkhan@gmail.com \\ ORCID ID 0000-0002-5040-0091
}

Timur Apendiyev

National Academy of Sciences of the Republic of

Kazakhstan. E-mail: timur.apendiev@mail.ru ORCID ID 0000-0002-4279-3921

\title{
Study of the problem of the formation of spiritual and moral qualities of high school students
}

\begin{abstract}
This article discusses the problem of studying the formation of spiritual and moral qualities of a person in philosophical, psychological and pedagogical aspects. In philosophical, religious studies, psychological, and pedagogical studies, the problem of studying the formation of spiritual and moral qualities was always relevant, and the study of this problem goes into the depths of human civilization. The conceptual ideas of classical educators and psychologists in understanding the nature of spirituality and morality are presented. And also considered the age characteristics of high school students in the process of their spiritual and moral formation. An analysis of the state of knowledge of the problem of the formation of spiritual and moral qualities of a person in foreign and domestic psychological and pedagogical literature showed that the spiritual and moral qualities of a person are a manifestation of the basic categories in psychology and pedagogy, that is, a manifestation of universal values in the structure of the personality, considered as the basic components of spiritual and moral personality of a high school student.

Keywords. Spirituality, morality, universal values, spiritual and moral qualities, harmonious all-round development, attitude to values, manifestation, activity in spiritual and moral activity.

Cite this article as: Akhmetova A., Toktaubay A., Kassymova G., Apendiyev T., (2020). Issledovaniye problemy formirovaniya dukhovno-nravstvennykh kachestv starsheklassnikov [Study of the problem of the formation of spiritual and moral qualities of high school students]. Challenges of Science. Issue III, p.: 76-82. https://doi.org/10.31643/2020.011
\end{abstract}

Ахметова A.

КазНПУ имени Абая, Казахстан

E-mail: aig.31@mail.ru

ORCID ID 0000-0002-9292-5515

Касымова $\Gamma$.

КазНПУ имени Абая, Satbayev University, Казахстан E-mail: g.kassymova@satbayev.university

ORCID ID 0000-0001-7004-3864
Токтаубай А.

КазНПУ имени Абая, Казахстан

E-mail: fertkhan@gmail.com

ORCID ID 0000-0002-5040-0091

Апендиев Т.

Национальная академия наук Республики

Казахстан. E-mail: timur.apendiev@ mail.ru ORCID ID 0000-0002-4279-3921

\section{Исследование проблемы формирования духовно-нравственных качеств старшеклассников}

\footnotetext{
Абстракт. В данной статье рассматривается проблема изучения формирования духовно-нравственных качеств личности в философском, психолого-педагогическом аспектах. В философских, религиоведческих, психологических, педагогических исследованиях проблема изучения формирования духовно-нравственных качеств была всегда актуальна, и изучение данной проблемы уходит в глубинные пласты человеческой
} 
цивилизации. Представлены концептуальные идеи классических педагогов и психологов в понимании природы духовности и нравственности. А также рассмотрены возрастные особенности старшеклассников в процессе их духовно-нравственного становления. Анализ состояния изученности проблемы формирования духовнонравственных качеств личности в зарубежной и отечественной психолого-педагогической литературе показал, что духовно-нравственные качества личности являются проявлением базовых категорий в психологии и педагогики, то есть проявлением общечеловеческих ценностей в структуре личности, рассматриваемых как базовые составляющие духовно-нравственной личности старшеклассника.

Ключевые слова. Духовность, нравственность, общечеловеческие ценности, духовно-нравственные качества, гармоничное всестороннее развитие, отношение к ценностям, проявление, активность в духовнонравственной деятельности.

В формировании духовно-нравственных качеств личности особое место занимают духовные ценности, имеющие общечеловеческую значимость. Если обратиться к истории развития данной проблемы, то мы замечаем, что при смене различных формаций развития общества общечеловеческие ценности не теряли своей актуальности и всегда были важным компонентом духовного наследия всего человечества и передавались из поколения в поколение.

В содержании народной педагогики всех народов мира главной целью воспитания рассматривалось воспитание гуманного человека посредством устного народного творчества, нравственные идеалы, религиозные традиции, созданием духовной и нравственной обстановки для развития духовно-нравственной личности. В педагогике особо важным положением рассматривалось воздействие среды, народных традиций и обычаев, живого примера.

Не утратили актуальности философские учения о нравственности Сократа, Аристотеля. По мнению философа Сократа счастье в жизни человека возникает путем духовного порядка и гармонии души. И поэтому сущность человек и цель человека он рассматривал как проявление его духовной жизни, а душу человека как «способность осозновать, проявлять мыслительную активность, быть совестливым, добродетельным»[1]. Он через организацию диалога призывал людей к осознанию своей высшей природы, то есть своей духовности, призывал всех прислушиваться к внутреннему голосу совести, которая развивает в человеке справедливость (знание, как соблюдать законы мироздания). И таким образом, через познание своей внутренней духовной природы, через самопознание, он человек может совершенствовать свои нравственные качества, свои добродетели. Отсюда следует: самопознание, постоянный поиск самого себя с помощью сократовского диалога и диалектического метода совместного поиска истины способствует совершенстованию духовно-нравственных качеств [2, С.155-178]. Российские философы Н.А.Бердяев, И.А.Ильин в своих трудах отмечали, что человеку от природы присуща способность реализовать духовное. По их мнению, духовность проявляется в стремлении к истине, добру, красоте. Они утверждали, что духовно насыщенная личность - это личность, осознавшая обсолютные ценности.

Дж. Локк в своем труде «Мысли о воспитании» основными духовно-нравственными качествами личности рассматривал благожелательность, гуманное отношение к людям, правдивость, милосердие. В научном труде «Лингард и Гертруда» известный педагог Г. Песталоцци отметил необходимость воспитания у подрастающего поколения милосердия, сострадательности, доброжелательного отношения к окружающему миру, развитие нравственных чувств и наклонностей. Изучением ступени нравственного развития личности занимался Э.Эриксон на каждой ступени личность обладала определенными показателями и др. Исследованием моральной компетентности занимался Ж.Пиаже, описание уровней и этапов развития нравственности сделал Л.Кольберг.

В начале XX века казахские ученые-просветители, ученые-педагоги Ж. Аймауытов [3], М. Жумабаев [4], М. Дулатов [5], А. Байтурсынов [6], Ш. Кудайбердиев [7] в своих трудах изучали человеческие качества. Духовное наследие казахских мыслителей, ученых представляет собой образовательно-воспитательное содержание, в котором рассматривалось проблема формирования духовно-нравственных качеств личности, способствование достижению счастья как основы духовного совершенствования личности.

Ы. Алтынсарин следовал педагогическим идеям Коменского, который считал, что «усвоение добродетелей, должно начинаться с самой ранней юности» [8]. Вся педагогическая деятельность Алтынсарина представлена изучением сущности нравственности, гуманизма, смысла человеческой жизни, нравственных мотивах поведения, воспитания высоконравственной личности. Он рассматривал духовно-нравственные качества личности как, трудолюбие, патриотизм, гуманизм, честность, скромность, справедливость. 
Познание истины, через «изучение мудрости, которое вызывает и делает нас сильными и великодушными» по Коменскому является непосредственной задачей школы. Согласно его идее, Алтынсарин осознавал, что «от хорошей постановки дела в начале, будут зависеть и последствия» [8]. Он утверждал о том, что поступки и поведение людей должны служить примером для других, иначе говоря, они должны быть честными, справедливыми, служить обществу.

Казахский философ Машхур Жусуп Копеев (1858 - 1931), рассуждая о сущности духовности и нравственности, старался понять смысл человеческого бытия и счастья, мотивов поведения и поступков человека. Всю свою творческую жизнь Машхур Жусуп Копеев посвятил делу просвещения казахского народа и утверждению в обществе идеи об изначальном единстве сердца и разума, то есть путь к миру требует не только духовного, но и интеллектуального испытания, постоянного поиска и преодоления сомнений [9]. Наследие С.Торайгырова несет идеи человечности, по его определению, нравственный выбор определяется самим человеком. Ему самому решать подчиниться обстоятельствам или попытаться занять активную позицию в жизни, сделать свой нравственный выбор [9]. По мнению, К.Д. Ушинского в ребенке необходимо формировать гуманность, трудолюбие, дисциплинированность, честность, правдивость, чувство ответственности, чувство собственного достоинства, сочетаемое со скромностью. Он считает, что нравственность духовна, и потому она добродетельна [10]. Педагогические гуманистические положения К.Д.Ушинского оказали огромное воздействие на становление гуманистической педагогики в конце XIX-XX века.

$\mathrm{B}$ начале $\mathrm{XX}$ века после победы Октябрьской социалистической революции формирование духовно-нравственных качеств личности начали рассматривать в рамках коллективного сосуществования с позиции классовых идей. И формирование духовно-нравственных качеств человека новой формации стало ключевой в идейно-воспитательном процессе нового социалистического государства. И поэтому формирование коллективизма в структуре личности советского человека рассматривалось в контексте воспитания «всесторонне развитого, внутренне дисциплинированного человека, который способен чувствовать, четко мыслить и действовать организованно вместе с коллективом» [11, С. 179.].

В рамках коллективистического подхода в воспитании нового гражданина социалистического государства А. С. Макаренко преследовал идею формирования нравственного сознания учащихся. А.С.Макаренко рекомендовал тренировать нравственные привычки, деловые, дружественные, товарищеские отношения в коллективе, основанные на доверии и уважения к личности воспитанника. В сотрудничестве взрослых и детей реализовывалась нравственная идея, социальная направленность. Для формирования духовно-нравственных качеств старшеклассников А. С. Макаренко рассматривал главным условием создание духовной основы для развития духовных потребностей.

В исследованиях ученых-психологов и педагогов существуют разные подходы к исследованию духовно-нравственных качеств личности, а в особенности к диагностике и проблеме организации работы психологов, педагогов, социальных педагогов по формированию нравственных качеств учащихся (Фридман Л.М.). Поэтому психологи отметили ключевое в формировании духовнонравственных качеств личности - формирование отношения к общечеловеческим иенностям. Категорию «отношение» начали рассматривать в деятельностном аспекте С. Л. Рубинштейн, А. Н. Леонтьев, В. В. Давыдов. В этой связи, отношение к ценностям рекомендовали формировать в нравственной деятельности.

Созданная по руководством В. В. Давыдова и Д. Б. Эльконина система развивающего обучения своей главной целью ставит формирование и развитие у учащихся способностей, личностных качеств. В ее основе лежит положение о том, что развитие человеческих способностей может осуществляться только в деятельности. Поэтому духовно-нравственное образование должно строиться преимущественно в деятельностной форме. Ученые, которые вели свои исследования в рамках системного подхода (Б.Г. Ананьев, Б.Ф. Ломов) ведущей категорией в понимании нравственного развития личности рассматривали психические явления, психические свойства как проявление отношения человека к окружающему миру [12]. В. Н. Мясищев содержание отношения объяснял особенностями субъекта и объекта отношений, а сами отношения позволяли выявить связь человека с окружающим миром и окружающими людьми, сами отношения проявлялись в деятельности, и поэтому содержание отношений раскрывало особенности самого человека, то есть его качества. Таким образом, ценностные отношения раскрывали значимость и смысл духовно-нравственной деятельности человека, превращаясь в его личностные ценности, личностные смыслы. Поэтому в рамках данного подхода, нравственные отношения рассматривались как отношения к человеку как высшей ценности.

В рамках методологического подхода изучения нравственности личности на идее самодетерминации, саморазвития, самостроительства, самоактуализации привело к формулированию 
концепций нравственного развития личности, связанных с гуманитарными науками. Воспитание нравственного человека через содержание цикла гуманитарных предметов возвратили в психологическую науку понятия «совесть», «честь», «духовность», «нравственность», «душа» (Б.С. Братусь, А.В. Петровский, В.И. Слободчиков, В.А. Петровский, В.П. Зинченко, В.И. Колесников, В.С. Мухина и др). Деятели данного направления считали, что нравственное воспитание личности учащегося возможно через усвоение нравственных ценностей как составной части культуры.

Исследованием педагогических средств формирования духовно-нравственных качеств школьников занимались М.Н. Аплетаев, Е.В. Веселова, Т.И. Власова, Коваль Н.А., Новикова Л.И., Т.И. Петракова, И.А. Соловцова. Н.Е. Щуркова в своем исследовании для формирования у старшеклассников духовно-нравственных качеств предложила ориентировать их на общечеловеческие ценности.

Как утверждает Ш.А.Амоношвили, создавший свою школу «Гуманной педагогики», основу воспитательно-образовательной программы, ориентированной на общечеловеческие ценности, воспитание гражданина - патриота своей страны. Самым главным является формирование отношения к общечеловеческим ценностям, которые проявляются в человеке как духовно-нравственные качества. В Москве на XI Международных педагогических чтениях в январе 2012 года Ш.А.Амонашвили отметил, что настало время, когда педагоги должны рассмотривать фундаментальное понятие, как духовный гуманизм. «Духовность есть сугобо личностное состояние внутреннего мира каждого человека. На основе духа и духовности совершенствуется в нем духовная жизнь, вовлекая в себя мысли, чувства, переживания, впечатления, увлечения, вкусы, отношения, устремления, мечты...Духовность объединяет все, что происходит в сознательном и подсознательном мирах человека» [13]. Образовательная концепция Ш.А.Амонашвили построена на гармоничном и равноправном союзе и содружестве Учителя и Ученика, где общечеловеческие ценности Истина, Мудрость и Красота представляются как естесственное состояние души и сердца опытного наставника, открытого для восприятия ребенка, потому что союз учителя и ученика - это присутствие духа сотворчества в познании универсальных законов бытия. Он напоминает учителям, что процесс образования должен полностью быть пропитан возвышенными и утонченными образами, которые питают душу и сердце ребенка и ведут его к раскрытию и проявлению заключенного в нем самом собственного духовного образования.

Казахстанская ученая Мукажанова Р.А., проведя сравнительный анализ понятий «нравственность» и «духовность», делает вывод, что данные категории тесно связаны между собой: нормы и принципы нравственности получают идейное обоснование и выражение в идеалах добра и зла, являющиеся категорями духовности. Мукажанова Р.А. считает, что через «приобщение старшеклассников к общечеловечким ценностям можно у них развивать духовно-нравственные качества» [14].

Так, она считает, что нравственность имеет своим источником духовность и является ее внешним проявлением. В педагогическом обиходе духовность характеризуется как проявление «человеческого в человеке». «Духовность - это то, что возвышает личность над физиологическими потребностями, этическим расчетом, рациональной рефлексией, то, что относится к высшей способности души человека, что заложено в основание его личности... Если духовность характеризует высшие, внутренние устремления личности, то нравственность - сфера ее внешних связей: отношений с людьми и обществом, что, в свою очередь, связано с гуманностью» $[14, \mathrm{C} .21]$.

Ссылаясь на исследования возрастной психологии и педагогики рассмотрим особенности развития старшеклассников в контексте формирования их духновно-нравственных качеств. Старшеклассники относятся к возрастному периоду ранней юности. Данный возрастной период рассматривается как стадия развития, которая начинается с полового созревания и заканчивается наступлением взрослости. В нашем исследовании исследование физиологических особенностей старшеклассников не является главной задачей. Мы рассмотрим социально-психологические характеристики, которые выступают механизмом обеспечения условий для формирования духовнонравственных качеств старшеклассников. Основным новообразованием является «новый тип строения личности и ее деятельности, психические и социальные изменения, которые впервые возникают на данном возрастном этапе и определяют сознание ребенка и его отношение к среде». Согласно теории Л.С.Выготского, развитие высших психических функций осуществляется в ходе освоения ценностей, которые влияют на формирование новообразования: «развитие самосознания» в условиях определенной «социальной ситуации развития». Таким образом, изучение психологических и педагогических трудов о проблеме развития возрастных особенностей старшеклассников позволил нам 
выделить самые основные новообразования данного возраста с учетом социальной ситуации развития личности старшеклассника.

Основным новообразованием юношеского возраста является развитие самосознания, открытие своей «Я-концепции», развитие рефлексии, осознание своих возможностей и индивидуальных особенностей. Изучение себя как целостной личности, формирование готовности к самоопределению, профессиональное самоопределение. Рефлексия как функция сознания проявляется в деятельности и рассматривается как личностная характеристика субъекта деятельности, его нравственности. Таким образом, рефлексия - «самосознание человека, осмысление собственных действий, поступков, самопонимание, понимание другой личности и ...». Рефлексия позволяет погружаться в себя, в свой внутренний мир, в свои переживания, поэтому рефлексирующий человек обращается в свой духовный опыт. А это самое ключевое в формировании духовно-нравственных качеств личности. Таким образом, в юношеском возрасте проявляется рефлексивное отношение к окружающему миру, к окружающим людям, а также к своему внутреннему миру, что позволяет познать себя, свои качества как нравственной личности, как личности ориентированной на общечеловеческие ценности.

Старший школьный возраст - это ранняя юность (16-17 лет), время выбора жизненного пути, выбора нравственных ориентиров [15].

Для данного возраста, как мы уже выше рассматривали, характерна социальная ситуация развития: готовность войти в самостоятельную жизнь. Старшеклассники выбирают профессию, ориентиры в будущей профессиональной деятельности, определяет свое место в жизни. Он должен быть подготовлен к труду, семейной жизни, выполнению гражданских обязанностей. Образ «Я», который создает в своем сознании старшеклассник, разнообразный: физический образ «Я», духовный образ «Я», интеллектуальный образ «Я». Но нас интересует именно его духовный образ, проявляющийся в духовно-нравственных качествах. Познание себя, своих духовно-нравственных качеств приводит к формированию мотивационного и когнитивного компонентов «Я-концепции» формирование реального «Я». С данными компонентами связаны также поведенческий и оценочный компоненты.

Юношеский возраст является решающим этапом для формирования мировоззрения, рассматриваемый не только как система знаний и опыта, но и система убеждений, переживаний, которые сопровождаются чувством их истинности, пониманием смысложизненных проблем. Целью является осознание мировоззренческих проблем «Кто Я?», «Для чего живу?», «Кем быть?», «Каким быть?», определение общественной направленности личной жизни, идеал служения. Открытие своего внутреннего мира, его эмансипация от взрослых - главное приобретение юности. У старшеклассников проявляется склонность к самоанализу, потребность к систематизации, обобщать свои знания о себе, разобраться в своих чувствах, действиях, поступках. Одна их характеристик старшеклассника - это формирование самоуважения. На формирование самоуважения влияет общение со сверстниками.

Юность считается привилегированным возрастом дружбы, но сами старшеклассники считают настоящую дружбу редкой. Эмоциональная напряженность дружбы снижается при появлении любви. Также данный возраст характеризуется наличием кризиса, который возникает на рубеже школьной и новой взрослой жизни и проявляется в крушении жизненных планов (не поступил в вуз), в разочаровании правильности выбора специальности, в расхождении представлений об условиях и содержании деятельности и реальном ее протекании. В кризисе юности старшеклассники сталкиваются с кризисом смысла жизни. Отсутствие внутренних средств разрешения кризиса может привести к развитию негативных явлений, например, наркомании, алкоголизму и т.д.

Ученые в кризисе рассматривают и негативные, и позитивные стороны. Негативные стороны связаны с утратой привычных условий жизнедеятельности, а позитивные стороны - вступление в новую жизнь, становление индивидуальности, формирование гражданственности, сознательности, целенаправленного самообразования [16-24].

Самым главным в изучении возрастных особенностей старшеклассников надо отметить то, что в этом возрасте характерно формирование нравственных убеждений на основе нравственных идеалов, данный возраст сильно интересуется лицами героического типа, мировоззренческими и социальнополитическими идеями.

В работе со старшеклассниками педагог сосредотачивает свое внимание на актуализации полученных знаний, умений и навыков по нравственно-духовному образованию, связанных с различными аспектами социально-политической, экономической и культурной жизни общества. Это связано с психологическими особенностями развития самосознания и самоопределения старшеклассника, характеризующиеся сензетивностью для формирования новообразований в структуре личности, которые касаются ориентации в выше указанных сферах жизни общества. То есть 
по окончании школы у старшеклассников складываются убеждения, мировоззрение, система социальных установок и позиций, определяющих его отношение к миру, к людям, к самому себе, к социальным, политическим, экономическим и другим событиям, происходящих в обществе, на земле, во вселенной. Они, становясь элементом личностного, социально-нравственного, гражданского самоопределения личности, носят мировоззренческий характер. Духовно-нравственное становление личности старшеклассника невозможно без его гражданской самоидентификации, заключающейся в объединении представлений о «гражданском - я», то есть всего того, что знает о себе как о гражданине. Приоритетные ценности, в этом возрасте - человечество, общество, отечество, культура, мир, земля, вселенная, знание и труд.

Таким образом, все ученые-педагоги и психологи рассматривают вопросы осознания духовности, как основы формирования духовно-нравственных качеств личности старшеклассника.

Так, вполне стало ясно то, что педагогическая и психологическая наука всегда интересовалась проблемой духовно-нравственного воспитания молодежи на всех уровнях системы образования. Поиски таких систем воспитания и образования осуществлялись на протяжении всей истории человечества, начиная с древнейших времен, выдающимися личностями. В этом направлении, высказала и свое мнение, и казахстанская ученая-педагог А.А.Бейсенбаева: «Гуманизация образования неотрывна от глубокой гуманитаризации его содержания, которая обеспечивается обращением школы к национальной и мировой культуре, духовным ценностям, что предполагает возрастание роли учебных предметов, формирующих духовную культуру личности любого народа во всем ее богатстве и многообразии, обогащение естественных и технических дисциплин экологическими и социальнозначимыми аспектами».

Глубокое отражение в сознании старшеклассника знаний об общечеловеческих ценностях с опытом нравственного поведения является результатом системной работы по нравственно-духовному образованию, в процессе целенаправленного психолого-педагогического воздействия на эмоционально-ценностную, потребностно-мотивационную, интеллектуальную, поведенческую и волевую сферу личности. Такое воздействие по осмыслению сущности общечеловеческих ценностей способствует духовно-нравственному развитию старшекласников.

Ссылка на данную статью: Ахметова А., Токтаубай А., Касымова Г., Апендиев Т., (2020). Исследование проблемы формирования духовно-нравственных качеств старшеклассников. Challenges of Science. Issue III, p.: 76-82. https://doi.org/10.31643/2020.011

\section{Литературы}

1. Платон. Диалоги Сократа - М.: Мысль, 2007.

2. Гутманн Д. Логотерапия для профессиональной помощи. Социальная работа, наполненная смыслом / Пер. С англ. Т.Кондратьевой, М.Хабаровой, С. Штукаревой. - М.: Издательство «Новый Акрополь», 2016. - С.264. - (Логотерапия и экзистенциальный анализ)., С.155-178

3. Аймауытов Ж. Сочинения (на каз.яз.) - Алматы: Жазушы, 1989. - 560 с.

4. Жумабаев М.Педагогика. - Алматы:Рауан, 1993. -112б.

5. Дулатов М.Шы5армалары. - Алматы: Жазушы, 1991. - 384 б.

6. Байтұрсынов А. Ақ жол. - Алматы: Жалын, 1991. - 384б.

7. Құдайбердиев Ш. Шығармалары. /Құрастырған М.Жармұхамбетов, С.Дәутов. - Алматы, 1988. -560 б.

8. Алтынсарин Ы. Собрание сочинений. Т.2. - Алма-Ата: Наука, 1976. - 423

9. Көпеев М.Ж. Адам мен жұлдыздар арақатынасы // Қазақ тарихы. - Алматы, 1995. - №6.-24с., С.24

10. Ушинский К.Д. О народности в общественном воспитании. - Педагогические сочинения в 6 т. -Т.1. - М.: Педагогика, 1988. -566c. - С.85

11. Макаренко А. С. Сочинения: В 7 т. - М., 1958. - Т. 5. - С. 179.

12. Ломов Б.Ф. Методологические и теоретические проблемы психологии. - М.: Наука, 1984. - 444 с.

13. Амонашвили Ш.А. Вдохновение и творчество - путь обновления образования // 11 Международные педагогические чтения. - М., 2012.

14. Мукажанова Р.А. Гуманистическая направленность обучения старшеклассников. - Алматы: ННПООЦ «Бобек», 2015. $-167 \mathrm{c}$.

15. Кулагина И.Ю., Колюцкий В.Н. Возрастная психология: Полный жизненный цикл развития человека: учеб. Пособие для студ. Высш. Учеб. Заведений. - М., 2001с.].

16. Слободчиков В.И., Исаев Е.И. Основы психологической антропологии. Психология развития человека: Развитие субъективной реальности в онтогенезе: Учеб. Пособие для вузов. - М., 2000. 
17. Kenzhaliyev, B. K., Surkova, T. Y., \& Yessimova, D. M. (2019). Concentration of rare-earth elements by sorption from sulphate solutions. Kompleksnoe Ispol'zovanie Mineral'nogo syr'â/Complex Use of Mineral Resources/Mineraldik Shikisattardy Keshendi Paidalanu, 3(310), 5-9. https://doi.org/10.31643/2019/6445.22

18. Apendiyev T.A., \& Abdukadyrov N.M. (2020). During the first world war germany and austria - hungary prisoners of the aulieata county. The Bulletin, 1(383), 218-225. https://doi.org/10.32014/2020.2518-1467.27

19. Apendiyev, T.A.; Zhandybaeva, S.S.; Tulebaev, T.A.; Abykenova, K.E. (2017). The Migration of Germans to Kazakhstan in the end of XIX -beginning XX century. Bylye Gody, Volume 44, Issue 2, 2 June 2017, Pages 568-575. https://doi.org/10.13187/bg.2017.2.568

20. Apendiyev, T. A., Smagulov, B. K., Kozybayeva, M. M. (2019). Study of some subethnic and genealogical groups of Kazakhs in pre-revolutionary Russian historiography (XVIII - early XX century). The Bulletin, 6(382), 346-354. https://doi.org/10.32014/2019.2518-1467.180

21. Kenzhaliev B.K., Kul'deev E.I., Luganov V.A., Bondarenko I.V., Motovilov I.Y., Temirova S.S. (2019). Production of Very Fine, Spherical, Particles of Ferriferous Pigments from the Diatomaceous Raw Material of Kazakhstan. Glass and Ceramics, 76(5-6), 194-198. https://doi.org/10.1007/s10717-019-00163-w

22. Triyono, B.M., Mohib, N., Kassymova, G.K., Pratama, G.N.I.P., Adinda D., Arpentieva, M.R. (2020). The Profile Improvement of Vocational School Teachers' Competencies. Vysshee obrazovanie v Rossii = Higher Education in Russia. Vol. 29, no. 2, pp. 151-158. https://doi.org/10.31992/0869-3617-2020-29-2-151-158

23. Gasanova R.R. Kassymova G.K., Arpentieva M.R., Pertiwi F. D., Duisenbayeva Sh. S., (2020). Individual educational trajectories in additional education of teachers. Challenges of Science. Issue III, p.: 59-68. https://doi.org/10.31643/2020.009

24. Kassymova, G.; Triyono, B.; Dossayeva, S.; Akhmetova, A. (2019), Cognitive competence and electronic learning. "Challenges of Science". Issue II, 2019. Page 153-158. https://doi.org/10.31643/2019.030

\section{References}

1.Platon. Dialogi Sokrata - M.: Mysl', 2007.

2. Gutmann D. Logoterapiya dlya professional'noy pomoshchi. Sotsial'naya rabota, napolnennaya smyslom / Per. S angl. T.Kondrat'yevoy, M.Khabarovoy, S. Shtukarevoy. - M.: Izdatel'stvo «Novyy Akropol'», 2016. - S.264. - (Logoterapiya i ekzistentsial'nyy analiz)., S.155-178

3. Aymauytov ZH. Sochineniya (na kaz.yaz.) - Almaty: Zhazushy, 1989. - 560 s.

4. Zhumabayev M.Pedagogika. - Almaty:Rauan, 1993. -112b.

5. Dulatov M.Shy5armalary. - Almaty: Zhazushy, 1991. - 384 b.

6. Baytyrsynov A. Ak, zhol. - Almaty: Zhalyn, 1991. - 384b.

7. K, ұdayberdiyev SH. Shyġarmalary. /K ұrastyrg்an M.Zharmykhambetov, S.Doutov. - Almaty, 1988. -560 b.

8. Altynsarin Y. Sobraniye sochineniy. T.2. - Alma-Ata: Nauka, 1976. - 423

9. Kepeyev M.ZH. Adam men zhyldyzdar arak, atynasy // K, azak, tarikhy. - Almaty, 1995. - №6.-24s., S.24

10. Ushinskiy K.D. O narodnosti v obshchestvennom vospitanii. - Pedagogicheskiye sochineniya v 6 t. -T.1. - M.: Pedagogika, 1988. -566s. - S.85

11. Makarenko A. S. Sochineniya: V 7 t. - M., 1958. - T. 5. - S. 179.

12. Lomov B.F. Metodologicheskiye i teoreticheskiye problemy psikhologii. - M.: Nauka, 1984. - $444 \mathrm{~s}$.

13. Amonashvili SH.A. Vdokhnoveniye i tvorchestvo - put' obnovleniya obrazovaniya // 11 Mezhdunarodnyye pedagogicheskiye chteniya. - M., 2012.

14. Mukazhanova R.A. Gumanisticheskaya napravlennost' obucheniya starsheklassnikov. - Almaty: NNPOOTS «Bobek», 2015. $-167 \mathrm{~s}$.

15. Kulagina I.YU., Kolyutskiy V.N. Vozrastnaya psikhologiya: Polnyy zhiznennyy tsikl razvitiya cheloveka: ucheb. Posobiye dlya stud. Vyssh. Ucheb. Zavedeniy. - M., 2001s.].

16. Slobodchikov V.I., Isayev Ye.I. Osnovy psikhologicheskoy antropologii. Psikhologiya razvitiya cheloveka: Razvitiye sub"yektivnoy real'nosti v ontogeneze: Ucheb. Posobiye dlya vuzov. - M., 2000.

17. Kenzhaliyev, B. K., Surkova, T. Y., \& Yessimova, D. M. (2019). Concentration of rare-earth elements by sorption from sulphate solutions. Kompleksnoe Ispol'zovanie Mineral'nogo syr'â/Complex Use of Mineral Resources/Mineraldik Shikisattardy Keshendi Paidalanu, 3(310), 5-9. https://doi.org/10.31643/2019/6445.22

18. Apendiyev T.A., \& Abdukadyrov N.M. (2020). During the first world war germany and austria - hungary prisoners of the aulieata county. The Bulletin, 1(383), 218-225. https://doi.org/10.32014/2020.2518-1467.27

19. Apendiyev, T.A.; Zhandybaeva, S.S.; Tulebaev, T.A.; Abykenova, K.E. (2017). The Migration of Germans to Kazakhstan in the end of XIX -beginning XX century. Bylye Gody, Volume 44, Issue 2, 2 June 2017, Pages 568-575. https://doi.org/10.13187/bg.2017.2.568

20. Apendiyev, T. A., Smagulov, B. K., Kozybayeva, M. M. (2019). Study of some subethnic and genealogical groups of Kazakhs in pre-revolutionary Russian historiography (XVIII - early XX century). The Bulletin, 6(382), 346-354. https://doi.org/10.32014/2019.2518-1467.180

21. Kenzhaliev B.K., Kul'deev E.I., Luganov V.A., Bondarenko I.V., Motovilov I.Y., Temirova S.S. (2019). Production of Very Fine, Spherical, Particles of Ferriferous Pigments from the Diatomaceous Raw Material of Kazakhstan. Glass and Ceramics, 76(5-6), 194-198. https://doi.org/10.1007/s10717-019-00163-w

22. Triyono, B.M., Mohib, N., Kassymova, G.K., Pratama, G.N.I.P., Adinda D., Arpentieva, M.R. (2020). The Profile Improvement of Vocational School Teachers' Competencies. Vysshee obrazovanie v Rossii = Higher Education in Russia. Vol. 29, no. 2, pp. 151-158. https://doi.org/10.31992/0869-3617-2020-29-2-151-158

23. Gasanova R.R. Kassymova G.K., Arpentieva M.R., Pertiwi F. D., Duisenbayeva Sh. S., (2020). Individual educational trajectories in additional education of teachers. Challenges of Science. Issue III, p.: 59-68. https://doi.org/10.31643/2020.009

24. Kassymova, G.; Triyono, B.; Dossayeva, S.; Akhmetova, A. (2019), Cognitive competence and electronic learning. "Challenges of Science". Issue II, 2019. Page 153-158. https://doi.org/10.31643/2019.030 